\title{
Nepafenac in the Treatment of Ocular Inflammation Following Cataract Surgery (Pseudophakic Macular Oedema) - an Update
}

\author{
Hadi Kjærbo \\ Scandinavian Eye Center, Hellerup, Denmark; Department of Ophthalmology, Copenhagen University Hospital, Copenhagen, Denmark
}

DOI: https://doi.org/10.17925/EOR.2018.12.1.32

C ataract surgery is a hugely important means of preventing poor-quality vision or vision loss, especially in the elderly and people with diabetes. Pseudophakic macular oedema (PMO) is a comparatively infrequent complication occurring in $0.2-2.35 \%$ of patients, but the increasing scale of cataract surgeries worldwide makes it a widespread and significant problem. PMO can affect vision and, if untreated, can damage the retina and, less commonly, cause pain. Effective and convenient treatment for PMO, therefore, is an important issue. The pathophysiology of PMO is not fully understood, but may result from multiple factors including traction, irritation and disturbance of the blood-retinal barrier, leading to secretion of inflammatory factors which affect the posterior segment. Among the non-steroidal anti-inflammatory drugs used in the management of PMO is nepafenac (NPF). NPF is a unique prodrug and use of the $0.1 \%$ formulation given three times daily is supported by several key phase II and III clinical trials, in which prophylactic use resulted in lower incidence of PMO, better visual outcomes and lower central subfield macular thickness than vehicle alone. Several studies have also shown that $0.1 \%$ NPF provided superior efficacy compared with bromfenac, fluorometholone or ketorolac in the treatment of PMO. More recently, a $0.3 \%$ NPF formulation has been developed to provide more convenient once daily dosing. A phase III trial $(n=819)$ showed that $0.3 \%$ NPF was non-inferior to $0.1 \%$ NPF in terms of inflammation and proportion or patients who were pain-free with similar safety profiles for both doses. Other evidence from phase II and III vehicle-controlled, non-comparative trials also indicate the equivalence of frequent $0.1 \%$ NPF and the less frequent $0.3 \%$ NPF dosing. Greater use of the more convenient $0.3 \%$ NPF formulation may help improve patient adherence and consequently provide better outcomes in PMO.

\section{Keywords}

Pseudophakic macular oedema, inflammation, cataract surgery, non-steroidal anti-inflammatory drugs, $0.1 \%$ nepafenac, $0.3 \%$ nepafenac

Disclosures: Hadi Kjærbo is a consultant for Alcon and speaker for Novartis.

Acknowledgement: Medical writing support, including preparation of the drafts under the guidance of the author, was provided by James Gilbart of Touch Medical Communications.

Review Process: Double-blind peer review.

Compliance with Ethics: This study involves a review of the literature and did not involve any studies with human or animal subjects performed by any of the authors.

Authorship: All named authors meet the International Committee of Medical Journal Editors (ICMJE) criteria for authorship of this manuscript, take responsibility for the integrity of the work as a whole, and have given final approval to the version to be published.

open Access: This article is published under the Creative Commons Attribution Noncommercial License, which permits any non-commercial use, distribution, adaptation and reproduction provided the original author(s) and source are given appropriate credit. (c) The Authors 2018.

Received: 3 January 2018

Accepted: 26 March 2018

Citation: European Ophthalmic Review. 2018;12(1):32-8

Corresponding Author: Hadi Kjærbo, Scandinavian Eye Center, Hans Bekkevolds Alle 7, 2900 Hellerup, Denmark. E: Hadi@dadlnet.dk

Support: The publication of this article was supported by Alcon. The views and opinions expressed in the article are those of the authors and not necessarily those of Alcon.
Cataract is the most common cause of blindness (accounting for $51 \%$ of blindness) and cataract surgery involving removal of fogged lenses and replacement with synthetic intraocular lenses is one of the most common surgical procedures performed worldwide. ${ }^{1,2}$ This intervention is hugely important in tackling otherwise increasing levels of vision loss or poor vision quality resulting from cataracts, especially in the elderly and in people with diabetes. ${ }^{3-6} \mathrm{~A}$ negative aspect of cataract surgery, however, is pseudophakic macular oedema (PMO). PMO is considered by some ophthalmologists to be a fairly infrequent complication of cataract surgery, but it has a reported incidence that ranges from $0.2-20 \%$ in different studies. ${ }^{17}$ This variation arises for several reasons, especially the diagnostic method used, such as confirmation by clinical examination only, optical coherence tomography (OCT) or fluorescein angiography. ${ }^{1.7}$ In addition, the changing definition of PMO and various treatment and patient variables affect this rate. The use of phacoemulsification methods in particular has reduced this incidence range to $0.2-2.35 \% \%^{7-9}$ Even at this low incidence, the increasing scale of cataract surgeries (estimated to be $>20$ million performed worldwide in 2015) ${ }^{10}$ makes PMO a significant problem that should be managed effectively. PMO is detected more frequently when eyes are examined using angiography, rather than relying on clinical symptoms.

When PMO occurs, it may result in suboptimal or impaired vision after surgery. $8,9,11$ It is important therefore that preventive treatments are used to diminish this risk as much as possible and ensure a favourable outcome. Among the various treatments used to achieve this aim is the preventive use of the non-steroidal anti-inflammatory drug (NSAID), nepafenac (NPF). This is administered as $0.1 \%$ eye drops and has shown notable efficacy in reducing the incidence of post-cataract PMO in several clinical trials ${ }^{12-18}$ and in clinical use. It is now approved in this indication for patients with or without diabetes. ${ }^{19,20}$ This article will consider the problem of PMO following cataract surgery and its consequences. It will also provide an update and consider newer evidence supporting a higher dose of NPF (0.3\%) that can be dosed less frequently than the $0.1 \%$ formulation and will compare the efficacy and safety of both doses. 


\section{The pathophysiology and consequences of pseudophakic macular oedema}

The pathogenesis of PMO following cataract surgery is not completely understood, but the causes are likely to be multifactorial. ${ }^{7.8}$ These are believed to include: vitreous traction resulting from manipulation and incisions in the eye, ${ }^{21}$ functional disturbance of the blood-retinal barrier $(B R B)^{22}$ and inflammation mediated by prostaglandins. ${ }^{23}$ Surgery is known to cause some degree of irritation and trauma within the eye, especially to the iris. It is likely that various mediators of inflammation (prostaglandins, cytokines and other vascular permeability factors) are released from the anterior segment and move to the posterior, including the vitreous and retina, where they stimulate breakdown of the BRB and leakage of fluids to the perifoveal retinal tissues leading to inflammation..$^{8,24}$ Damage to the BRB leads to leakage and fluid accumulation in the central retina, which can result in vision impairment and even vision loss., 8,1,24-26

In most patients, PMO resolves without intervention. ${ }^{24}$ In some patients, however, more extensive leakage from the retina causes chronic inflammation that can lead to severe damage, which is irreversible. ${ }^{27}$ The reasons why most cases of PMO resolve but some become chronic are, as yet, unclear but they may be related to the presence of risk factors, as discussed below. PMO has traditionally been diagnosed using fluorescein angiography, but OCT accurately reveals swelling and thickening of the retina and cystic spaces (Figure 1) and is now the method of choice. Other methods include vitreous fluorometry and the retinal leakage analyser.

\section{Risk factors and incidence of pseudophakic macular oedema}

The risk of PMO is increased by various factors, especially rupture of posterior capsule, vitreous loss, iris incarceration, use of iris fixated lenses, active uveitis and diabetes. ${ }^{11}$ In one comparative cohort study $(n=93)$ in eyes with uveitis, active inflammation within 3 months prior to surgery significantly increased the risk of PMO compared with eyes without prior inflammation. ${ }^{28} \mathrm{~A}$ retrospective database study involving 81,984 eyes undergoing cataract surgery in the UK identified the highest risk factors for PMO. These included: epiretinal membrane (hazard ratio [HR]: 5.596), retinal vein occlusion (HR: 4.471) previous retinal detachment repair (HR: 3.926) and uveitis (HR: 2.878) (Figure 2). ${ }^{1}$

The reported incidence of PMO varies from approximately $0.1 \%$ to $2.35 \%$, but the rate of angiographic/asymptomatic PMO (with visible leakage from perifoveal capillaries) is up to 10 times greater. Use of a large incision instead of a small incision with phacoemulsification also increases the rate of PMO. ${ }^{8}$ This incidence does not appear to be affected with the use of laser or manual surgery. This was demonstrated in a study of 1,390 patients receiving cataract surgery, which found PMO in 15 eyes (1.1\%; 11 patients). There was also no difference in the incidence of PMO in patients receiving laser or conventional cataract surgery. ${ }^{29}$

The incidence of PMO appears to decrease with increasing age, as was highlighted in a database study of 13,556 patients (19,980 eyes) who received uncomplicated phacoemulsification during a 1-year period at community-based outpatient clinics within a region in France..$^{30}$ This study found a trend of decreasing PMO in older age groups: $2.38 \%$ in those aged $40-54$ years, $0.86 \%$ in those aged $\geq 85$ years; $p=0.0009$. The incidence of $\mathrm{PMO}$ was also higher in men than women (1.25\% versus $0.73 \% ; \mathrm{p}=0.002)$, but there was no difference in incidence between those with a history of diabetes than those without it ( $1.05 \%$ versus $0.90 \% ; p=0.48$ ). This gender difference is supported by the UK database study $(81,984$ eyes) that showed a higher incidence of PMO among males versus females $(1.391 \%$ versus $1.023 \% ; p=0.0019$ ).
Figure 1: Fluorescein angiograms and spectral domain optical coherence tomography images from a patient with pseudophakic macular oedema
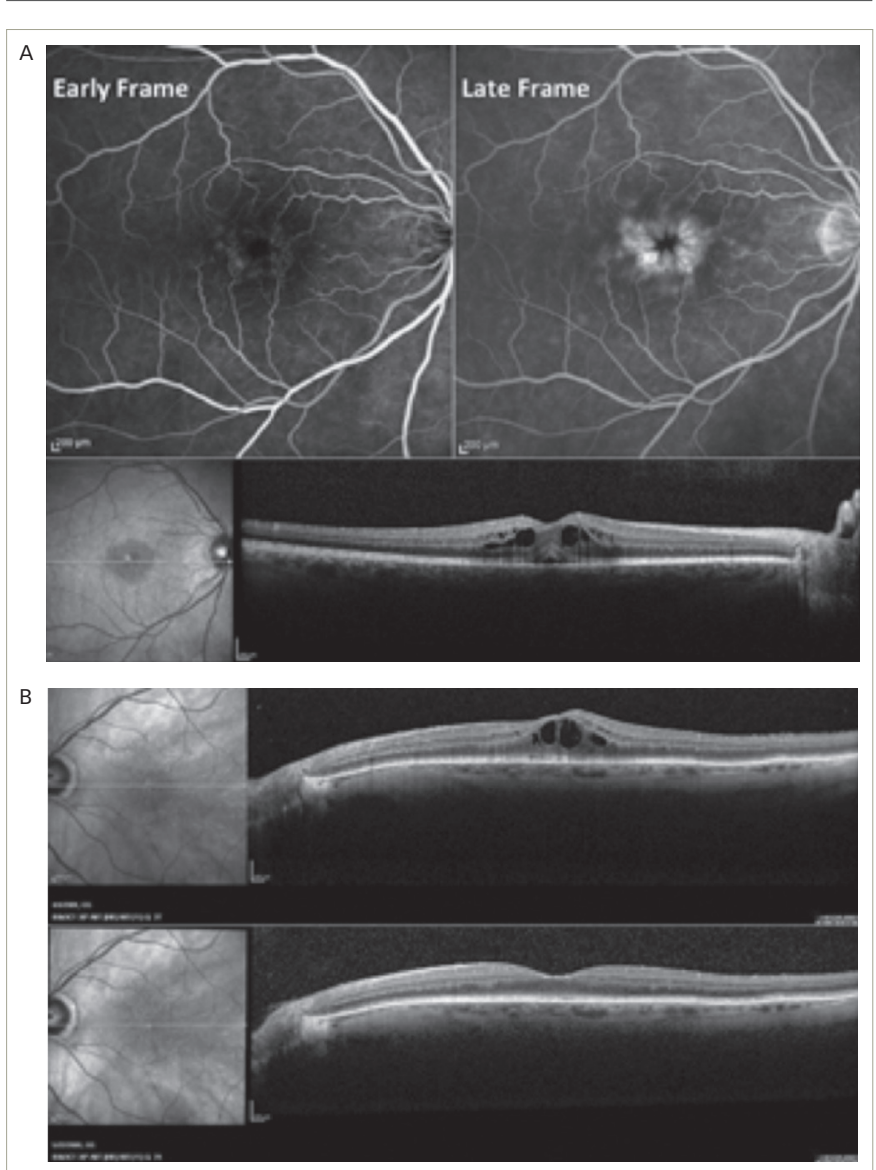

A: Right eye with PMO. Early frame discloses leakage of the perifoveal capillaries (upper left) that increases in size and intensity to a "petaloid" appearance in the later frame (upper right). SD-OCT shows cystoid spaces in the outer retina with a small amount of foveal subretinal fluid. B: SD-OCT of the left eye reveals cystoid macular oedema 6 weeks following cataract extraction (top) that resolved 6 weeks later (bottom). Reproduced with permission from Jeffery S Heier (Ophthalmic Consultants of Boston). ${ }^{54}$ $P M O=$ pseudophakic macular oedema; SD-OCT = spectral domain optical coherence tomography.

\section{Management of pseudophakic macular oedema}

The American Academy of Ophthalmology (AAO) and the American Society of Cataract and Refractive Surgery (ASCRS) consider that there is insufficient strong evidence to support the routine prophylactic use of anti-inflammatory drugs to prevent PMO following cataract surgery. ${ }^{31,32}$ Furthermore, a Cochrane review concluded that the value of adding topical NSAIDs to steroids or using them as an alternative to topical steroids with a view to reducing the risk of poor visual outcome after cataract surgery is uncertain. ${ }^{33}$ However, many ophthalmologists accept that prophylactic use of anti-inflammatory drugs is important in preventing PMO and report that this approach is effective. ${ }^{34-37}$ Such treatments include various topical NSAIDs or corticosteroids, and combinations of the two. These treatments have also been used in combination with anti-vascular endothelial growth factor (VEGF) agents such as bevacizumab in PMO. ${ }^{38}$ Prophylactic NSAIDs have shown varied efficacy in the prevention and treatment of PMO and have been used in these indications for many years. Frequently used examples of NSAIDs include: ketorolac, bromfenac, diclofenac, indomethacin, flubiprofen, nepafenac and suprofen. ${ }^{7.8}$ Some studies have provided strong evidence supporting such treatments. One example included 1,659 consecutive cataract surgeries performed by residents. ${ }^{39}$ In treating post-surgical cystoid macular oedema, the combination of an NSAID and a steroid resulted in significantly shorter 
Figure 2: Risk of pseudophakic macular oedema in non-diabetic patients with single co-pathological factors in a retrospective database study of 81,984 eyes undergoing cataract surgery

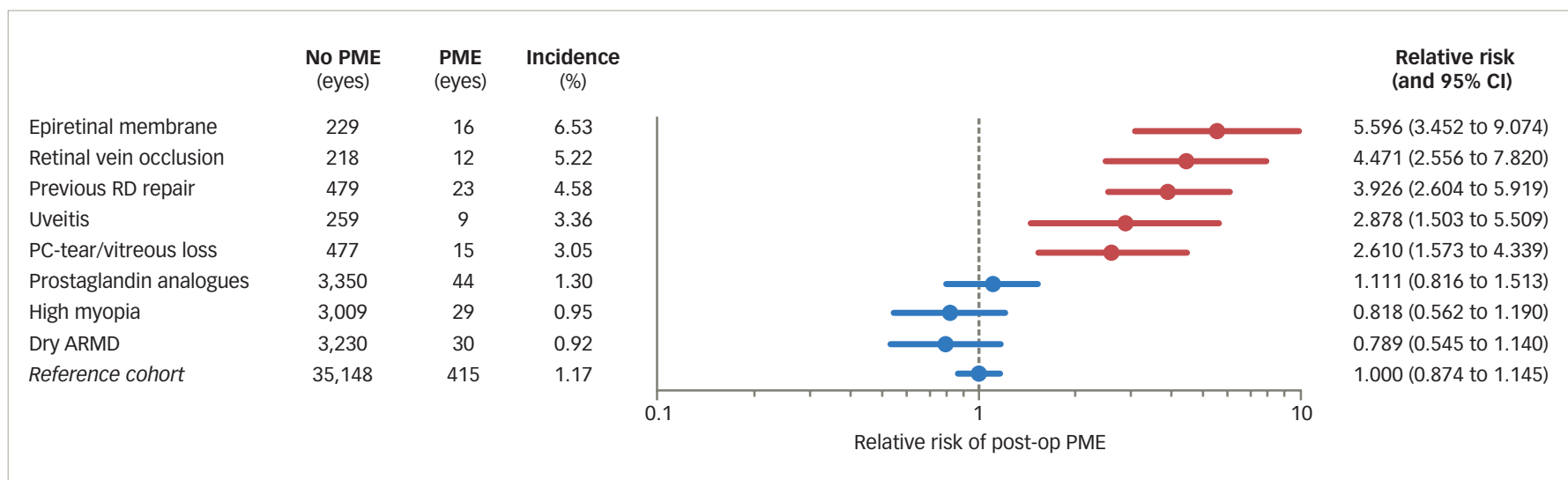

Reproduced under the the CC BY-NC-ND license from Chu et al., 2016.

$A R M D=$ age-related macular degeneration; $C l=$ confidence interval; $P C=$ posterior capsule; $P M E=$ pseudophakic macular edema $; R D=$ retinal detachment

resolution times than no treatment. On the other hand, some other studies evaluating the use of anti-inflammatory drugs before and after cataract surgery have been less well designed. As a result, the treatment is still considered controversial by some physicians and more studies are needed to verify the efficacy of anti-inflammatory treatments in PMO to justify their continued use. ${ }^{8,33}$ Once PMO becomes chronic, treatment has a high cost; prophylactic treatments significantly reduce these costs and reduce patient burden, particularly in those with preoperative diabetic macular oedema whose rates of $\mathrm{PMO}$ are substantially higher than those without it. ${ }^{40}$ These costs were emphasised by a retrospective analysis of the US Medicare files of 78,949 patients undergoing cataract surgery over a 2-year period. This study found that patients with diabetic macular oedema (DMO) had mean ophthalmic charges of US\$10,410 versus US $\$ 5,950$ for those without it $(p<0.0001)$.

\section{Nepafenac $0.1 \%$ - an established preventive treatment for macular oedema following cataract surgery}

Among the multiple NSAIDs that are available, topical 0.1\% NPF has shown efficacy in preventing PMO when started shortly before and continued after cataract surgery. ${ }^{41}$ Various clinical trials in recent years have demonstrated the benefits of NPF in this indication. ${ }^{13,14,18,42}$ NPF is a unique prodrug that rapidly penetrates the cornea and is converted to the active compound, amfenac. This molecule is target-specific and inhibits prostaglandin formation and consequent inflammation in both the anterior and posterior segments of the eye. The prodrug structure may reduce surface damage to the eye, which can be an issue with non-prodrug medications. NPF also inhibits retinal VEGF secretion and reduces neovascularisation. ${ }^{43-45}$

Several key phase II and III trials and a pooled analysis have supported use of NPF in the prevention and treatment of PMO (Table 1). Among these was a phase $\|$ randomised vehicle-controlled study $(n=263)$ that included patients who were treated with topical $0.1 \%$ NPF or vehicle from day 1 to day 90 post-surgery. ${ }^{17}$ Significantly fewer patients developed PMO in the NPF group than vehicle group (3.2\% versus 16.7\%; $p<0.001$ ) and fewer had best-corrected visual acuity (BCVA) reductions of $>5$ letters on days 30,60 and 90 ( $p=0.001-0.006$ ). Mean central subfield macular thickness (CSMT) mean and change in macular volume from baseline were also significantly lower with NPF (the mean maximum change for NPF was $18.9 \pm 19.5 \mu \mathrm{m}$ and for vehicle was $40.8 \pm 49.0 \mu \mathrm{m} ; \mathrm{p}<0.001)$. In addition, changes in macular volume were significantly lower with NPF $(p<0.001$ for days 30,60 and 90). No safety issues were identified.

A further key study was a phase III randomised vehicle-controlled study that included 175 patients with diabetes requiring cataract surgery and assigned to $0.1 \%$ NPF (three times daily, $n=87$ ) or vehicle (three times daily, $n=88$ ) (all received tobramycin and dexamethasone). ${ }^{15}$ At 90 days post surgery, significantly fewer NPF-treated patients developed PMO than vehicle-treated patients (5.0\% versus $17.5 \% ; p=0.01)$. The mean change in BCVA from baseline to day 90 was numerically greater for NPF but not significantly different $(+17.7$ versus +14.3 letters; $p=0.14)$. The 90-day treatment regimen with NPF effectively prevented PMO after cataract surgery and identified no new safety issues or trends.

\section{Comparative trials of nepafenac in the prevention of macular oedema following cataract surgery}

Several key clinical trials have compared NPF with another treatment or compared concomitant treatments used in addition to NPF. One such study was a retrospective investigation of patients receiving cataract surgery with phacoemulsification $(n=65)$ who were all given dexamethasone and netilmicin and were divided into treatment groups according to the additional NSAIDs that they received. Only patients receiving $0.1 \%$ NPF plus steroids showed a reduction in macular thickness $(-1.3 \% ; p=0.048)$ whereas it remained the same for those receiving steroids plus bromfenac, indomethacin or diclofenac $(-1.1 \%$ to $+1.2 \% ; p=0.19-0.74)$ but was increased in those treated with dexamethasone and netilmicin alone $(+4.3 \%, p=0.04) .{ }^{46}$ No side effects were observed in any group. It was concluded that NPF, bromfenac and indomethacin enhanced the efficacy of steroids used to reduce $\mathrm{PMO}$.

A phase $\|$ double-blind active controlled study directly compared $0.09 \%$ bromfenac with $0.1 \%$ NPF in terms of bioavailability and efficacy in patients undergoing phacoemulsification $(n=139) .{ }^{47}$ After 30 days, there was a significant difference in central retinal thickness when the two treatments were compared (252.0 versus $264.0 \mu \mathrm{m} ; \mathrm{p}=0.022$ ), indicating that NPF provided a greater effect than bromfenac on this parameter. However, there were no clinically relevant changes in the presentation of PMO and no significant alterations in intraocular 
Table 1: Summary of key clinical trials of $0.1 \%$ and $0.3 \%$ nepafenac in the prevention of macular oedema following cataract surgery

\begin{tabular}{|c|c|c|c|c|c|}
\hline Reference & Study design & Number of patients & Treatments & Endpoints & Key findings \\
\hline $\begin{array}{l}\text { Singh et al., } \\
2012^{17}\end{array}$ & $\begin{array}{l}\text { Multicentre phase } \\
\text { II randomised } \\
\text { vehicle-controlled }\end{array}$ & $\begin{array}{l}263 \text { adults with diabetes } \\
\text { who had received cataract } \\
\text { surgery }\end{array}$ & $\begin{array}{l}\text { NPF } 0.1 \% \text { or VHL three } \\
\text { times daily } 1 \text { day before } \\
\text { to } 90 \text { days post-surgery }\end{array}$ & $\begin{array}{l}\text { Percentage with } \mathrm{MO}(\geq 30 \% \\
\text { increase in central subfield } \\
\text { macular thickness from } \\
\text { baseline) and percentage with } \\
\text { decreases of }>5 \text { letters in BCVA } \\
\text { from day } 7 \text { to } 90\end{array}$ & $\begin{array}{l}3.2 \% \text { versus } 16.7 \% \text { developed } \mathrm{MO} \\
\text { with NPF versus VHL ( } p<0.001) \text {. Fewer } \\
\text { patients receiving NPF than VHL had } \\
\text { decreases in BCVA of }>5 \text { letters on days } \\
30,60 \text { and } 90 \text { ( } p<0.001,0.002,0.006 \text {, } \\
\text { respectively). Mean central subfield } \\
\text { thicknesses were significantly lower } \\
\text { with NPF. No new safety issues were } \\
\text { observed }\end{array}$ \\
\hline $\begin{array}{l}\text { Pollack et al., } \\
2017^{15}\end{array}$ & $\begin{array}{l}\text { Multicentre phase } \\
\text { III randomised } \\
\text { vehicle-controlled }\end{array}$ & $\begin{array}{l}175 \text { patients with diabetes } \\
\text { who had received cataract } \\
\text { surgery }\end{array}$ & $\begin{array}{l}\text { NPF } 0.1 \% \text { or VHL three } \\
\text { times daily } 1 \text { day before } \\
\text { to } 90 \text { days post-surgery } \\
\text { (all patients received } \\
\text { tobramycin } 0.3 \% \text { and } \\
\text { dexamethasone } 0.1 \% \\
\text { four times daily for } \\
2 \text { weeks after surgery) }\end{array}$ & $\begin{array}{l}\text { Primary: percentage with } \\
\text { MO ( } \geq 30 \% \text { increase in central } \\
\text { subfield macular thickness } \\
\text { from baseline) in } 90 \text { days; } \\
\text { Secondary: change in BCVA } \\
\text { baseline to day } 90\end{array}$ & $\begin{array}{l}5.0 \% \text { versus } 17.5 \% \text { developed } \mathrm{MO} \\
\text { within } 90 \text { days after surgery }(\mathrm{p}=0.01) \text {. } \\
\text { Mean change in BCVS was } 17.7 \text { letters } \\
\text { for NPF versus } 14.3 \text { letters for VHL } \\
(\mathrm{p}=0.14) . \text { No new safety issues were } \\
\text { observed }\end{array}$ \\
\hline $\begin{array}{l}\text { Modi et al., } \\
2014^{49}\end{array}$ & $\begin{array}{l}\text { Multicentre phase } \\
\text { III randomised } \\
\text { vehicle- and } \\
\text { active-controlled }\end{array}$ & $\begin{array}{l}817 \text { patients who had } \\
\text { received cataract surgery } \\
\text { with phacoemulsification }\end{array}$ & $\begin{array}{l}\text { NPF } 0.3 \% \text { once daily, } \\
\text { NPF } 0.1 \% \text { three times } \\
\text { daily or VHL from day - } 1 \\
\text { to day } 14 \text { after surgery } \\
\text { (extra drop of study } \\
\text { drug } 30-120 \text { minutes } \\
\text { after surgery) }\end{array}$ & $\begin{array}{l}\text { Primary: Percentage patients } \\
\text { with no inflammation at day } 14 ; \\
\text { Secondary: percentage pain } \\
\text { free at day } 14\end{array}$ & $\begin{array}{l}\text { At day } 14 \text {, for NPF } 0.3 \% \text { patients, } 68.4 \% \\
\text { had no inflammation and } 91 \% \text { were } \\
\text { pain free versus } 34.0 \% \text { and } 49.7 \% \text { of } \\
\text { VHL patients ( }<<0.0001 \text { ). NPF } 0.3 \% \text { was } \\
\text { non-inferior to NPF } 0.1 \% \text {. NPF } 0.3 \% \text { had } \\
\text { a safety profile comparable to NPF } 0.1 \%\end{array}$ \\
\hline $\begin{array}{l}\text { Singh et al., } \\
2017- \\
\text { Study } 1^{50}\end{array}$ & $\begin{array}{l}\text { Multicentre phase } \\
\text { III randomised } \\
\text { active-masked, } \\
\text { vehicle-controlled }\end{array}$ & $\begin{array}{l}615 \text { patients aged } \\
\geq 18 \text { years with diabetes } \\
\text { who had received } \\
\text { cataract surgery with } \\
\text { phacoemulsification }\end{array}$ & $\begin{array}{l}\text { NPF } 0.3 \% \text { or VHL once } \\
\text { daily starting } 1 \text { day } \\
\text { before to } 90 \text { days } \\
\text { post-surgery }\end{array}$ & $\begin{array}{l}\text { BCVA, development of MO } \\
\text { ( } \geq 30 \% \text { increase in } 219 \text { CSMT } \\
\text { from the } \\
\text { pre-operative baseline), } \\
\text { macular thickness and volume, } \\
\text { incidence of treatment failure }\end{array}$ & $\begin{array}{l}\text { At } 90 \text { days for NPF 0.3\% and VHL, } \\
\text { percentage patients with MO were } 2.3 \% \\
\text { versus } 17.3 \% \text { ( } p<0.001 \text { ). Percentage } \\
\text { with } \geq 15 \text { letter BCVA improvement } \\
\text { (versus baseline) were } 61.7 \% \text { versus } \\
43.0 \% \text { ( } p<0.001 \text { ). No unanticipated } \\
\text { adverse events were observed }\end{array}$ \\
\hline $\begin{array}{l}\text { Singh et al., } \\
2017- \\
\text { Study } 2 \\
\text { (in press) }^{55}\end{array}$ & $\begin{array}{l}\text { Multicentre phase } \\
\text { III randomised } \\
\text { active-masked, } \\
\text { vehicle-controlled }\end{array}$ & $\begin{array}{l}605 \text { patients aged } \\
\geq 18 \text { years with diabetes } \\
\text { receiving cataract surgery } \\
\text { with phacoemulsification }\end{array}$ & $\begin{array}{l}\text { NPF } 0.3 \% \text { or VHL once } \\
\text { daily starting } 1 \text { day } \\
\text { before to } 90 \text { days } \\
\text { post-surgery }\end{array}$ & $\begin{array}{l}\text { BCVA, development of MO } \\
\text { ( } \geq 30 \% \text { increase in } 219 \text { CSMT } \\
\text { from the pre-operative } \\
\text { baseline), macular thickness } \\
\text { and volume, incidence of } \\
\text { treatment failure }\end{array}$ & $\begin{array}{l}\text { At } 90 \text { days for NPF 0.3\% and VHL, } \\
\text { percentage patients with MO were } 5.9 \% \\
\text { versus } 14.3 \% \text { ( } p<0.001 \text { ). Percentage } \\
\text { with } \geq 15 \text { letter BCVA improvement } \\
\text { (versus baseline) were } 48.8 \% \text { versus } \\
50.5 \% \text { ( } p=0.671 \text { ). No unanticipated } \\
\text { adverse events were observed }\end{array}$ \\
\hline $\begin{array}{l}\text { Pooled } \\
\text { analysis } \\
\text { of studies } \\
\text { I and } 2^{56}\end{array}$ & & & & & $\begin{array}{l}\text { At } 90 \text { days for NPF } 0.3 \% \text { and VHL, } \\
\text { percentage patients with MO were } 4.1 \% \\
\text { versus } 15.9 \% \text { ( } p<0.001 \text { ). Percentage } \\
\text { with } \geq 15 \text { letter BCVA improvement } \\
\text { (versus baseline) were } 55.4 \% \text { versus } \\
46.7 \% \text { ( } p=0.003 \text { ) }\end{array}$ \\
\hline
\end{tabular}

BCVA = best-corrected visual acuity; $C S M T=$ central subfield macular thickness; $M O=$ macular oedema; $N P F=$ nepafenac; $V H L=$ vehicle.

pressure, lissamine green or fluorescein staining. For other parameters, pain, photophobia, conjunctival hyperaemia, chemosis, cellularity and corneal oedema had all disappeared by day 30 with both treatments. Overall in this study, bromfenac $0.09 \%$ and nepafenac $0.01 \%$ used after phacoemulsification showed similar clinical efficacy.

In a Japanese study, 59 patients receiving small incision cataract extraction and foldable intraocular lens implantation were randomised to fluoromethalone $0.1 \%$ or NPF $0.1 \% .{ }^{14}$ At 5 weeks, with NPF compared with fluoromethalone, the incidence of fluorescein angiographic cystoid MO was lower (14.3\% versus $81.5 \%$, respectively; $p<0.0001)$, the fovea was thinner $(p=0.0055)$ and anterior chamber flare was lower $(p=0.0304)$. In addition, the visual acuity recovery was significantly greater with NPF (80.0\%) than fluorometholone (55.2\%; $p=0.0395)$. This study therefore showed that NPF was more effective than fluorometholone in preventing angiographic PMO and that NPF provided a more rapid recovery in vision.

A study in India compared NPF with ketorolac in PMO. ${ }^{16}$ This study included 200 eyes in 200 patients undergoing phacoemulsification (including some patients with diabetes) with a mean age of 58-59.3 years and a low PMO risk (without ocular inflammation, diabetic or hypertensive retinopathy, ocular vascular disease, retinitis pigmentosa, previous intraocular surgery, vitreoretinal interface abnormalities or hypersensitivity to NSAIDS). Patients were randomised to post-operative $0.1 \%$ NPF 0.15 or ketorolac $0.4 \%$. At 1 month, post-operative macular 
Figure 3: Cumulative percentage of cures (A) and patients (B) who were pain free by visit in a phase III study $(n=1,636)$ comparing $0.1 \%$ and $0.3 \%$ nepafenac and vehicle to treat ocular inflammation and pain after cataract surgery

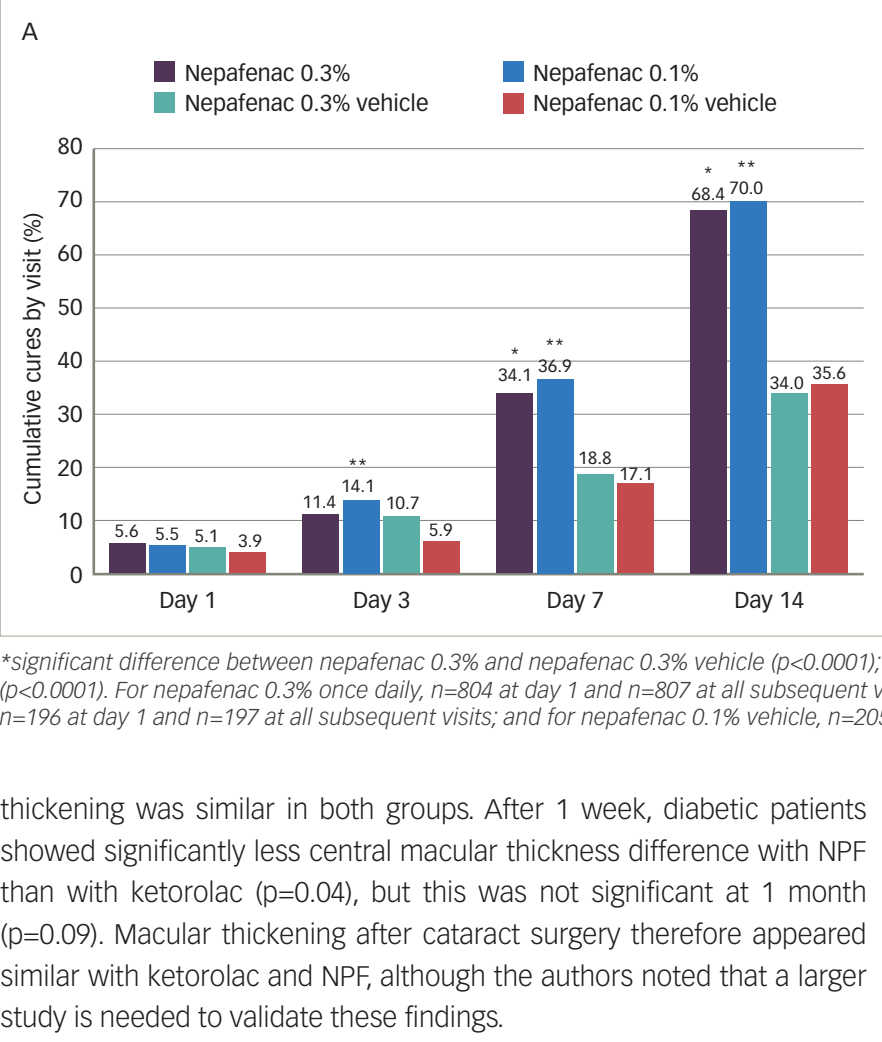

A meta-analysis of 11 randomised controlled trials that included a total of 1,165 patients with 1,175 cataract surgeries showed that topical $0.1 \%$ NPF is superior to ketorolac for ocular inflammation in terms of patient tolerability (conjunctival hyperaemia and ocular discomfort) following cataract surgery. ${ }^{48}$ However, the two drugs were found to be equally suitable for the management of anterior chamber inflammation, visual rehabilitation and intraoperative mydriasis.

\section{Evidence supporting a higher dose, less frequent dosing regimen of nepafenac $(0.3 \%)$ in the prevention of macular oedema following cataract surgery}

The $0.1 \%$ NPF formulation for PMO prevention/treatment is given three times daily. More recently, a higher concentration $0.3 \%$ formulation has been developed and approved to enable a more convenient once daily dosing. ${ }^{42}$ Some key phase III trials have compared the efficacy and safety of the $0.3 \%$ dose with the established $0.1 \%$ dose.

The first key trial for $0.3 \%$ dosing was a double-masked,vehicleand active-controlled study at 65 centres in the US and Europe (NCT01109173), in which patients receiving cataract surgery were randomised to $0.1 \%$ NPF three times daily $(n=819)$ or $0.3 \%$ NPF once daily from day 1 to day $14 .{ }^{49}$ Other patients $(n=200$ and $\mathrm{n}=206$ received the respective vehicles only). For patients receiving $0.3 \%$ NPF versus vehicle at day 14 significantly more had no inflammation (68.4\% versus $34.0 \% ; p<0.0001)$ and significantly more were pain free (91.0\% versus 49.7\%; $p<0.0001$; pain free was defined as an ocular pain assessment score of 0 ). The proportions that were cured or pain free by visit are given in Figure 3. With $0.3 \%$ NPF there were also significantly fewer treatment failures $(p \leq 0.0012)$ and more treatment successes $(p \leq 0.0264)$ compared with vehicle. $0.3 \%$ NPF was non-inferior to $0.1 \%$ NPF for inflammation (95\% confidence interval [CI]: $-5.73-3.17 \%$ )

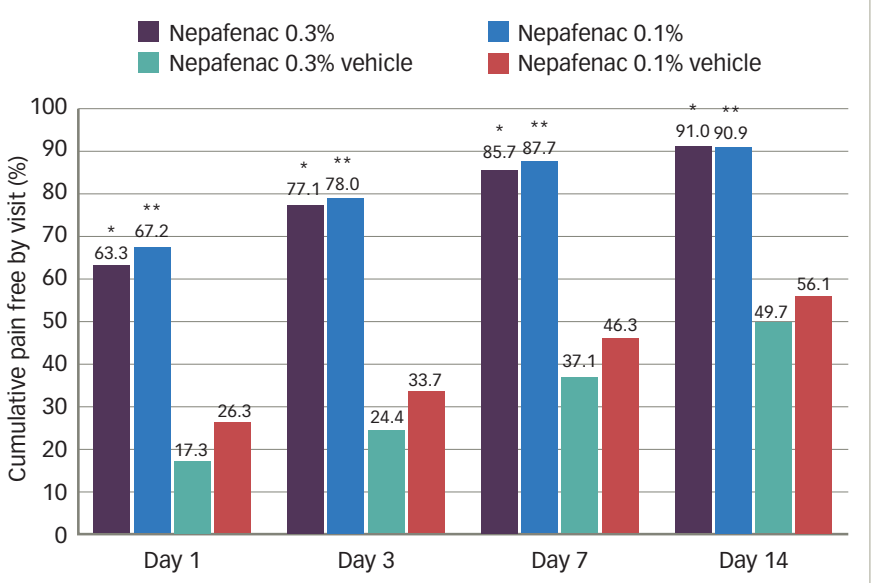


Figure 4: Effect of $0.3 \%$ nepafenac versus vehicle only in the prevention of macular oedema after cataract surgery in two phase III trials

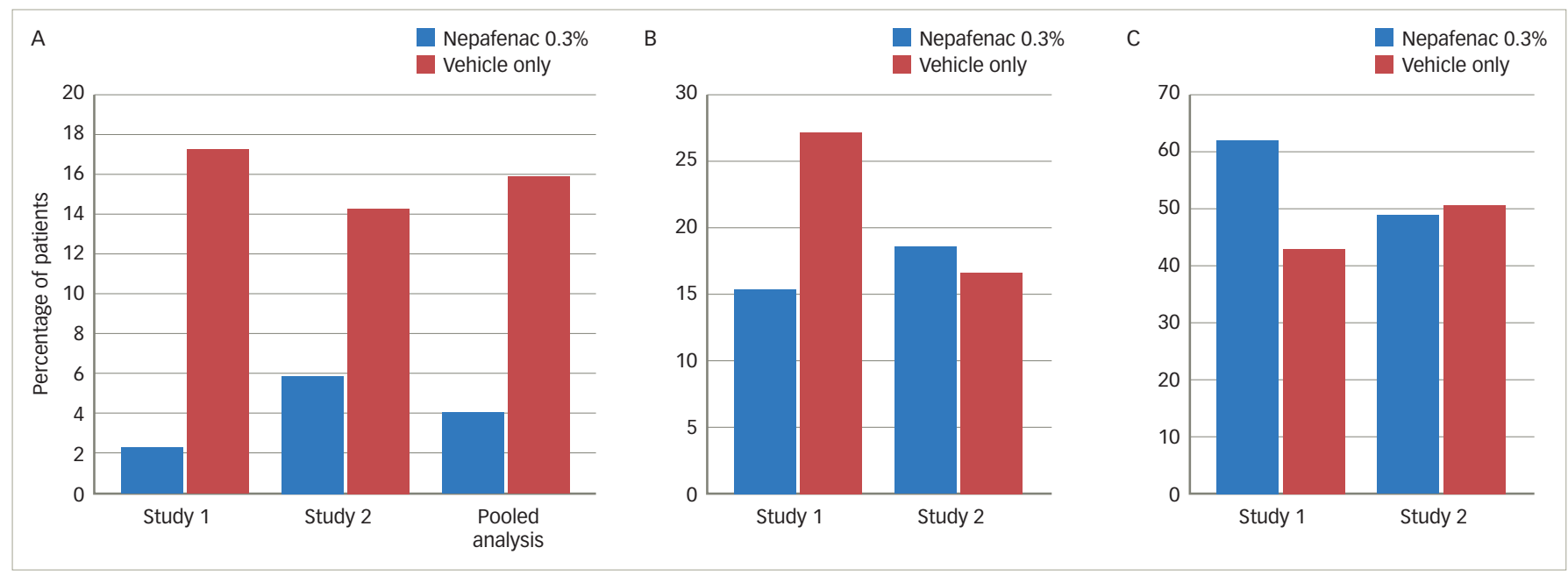

A: proportion who developed pseudophakic macular oedema; B: percentage of eyes with a BCVA loss of $>5$ and $>10$ letters from day 7 to any visit; C: BCVA improvement of $\geq 15$ letters from preoperative baseline to day 14 and maintained through day 90. BCVA = best-corrected visual acuity.

Reproduced under the CC BY-NC-ND license from singh et al., 2017.50

An additional randomised study of 1,000 eyes, conducted in the US recently, showed that prophylactic once-daily $0.3 \%$ NPF for 5 weeks after cataract surgery significantly reduced the incidence of cystoid macular oedema compared with placebo $(p=0.0001) .{ }^{51}$ This effect, however, was only seen in patients with preoperative risk factors (mainly pseudophakic cystoid macular oedema in the previously operated eye, diabetic retinopathy and vein occlusion).

Further evidence for the $0.3 \%$ NPF formulation comes from a 2013 literature search and analysis of clinical studies of NPF to reduce pain after cataract surgery, which concluded that the $0.1 \%$ and $0.3 \%$ NPF formulations appeared to be equally effective, but the $0.3 \%$ dose was more convenient yet with a slightly higher adverse event rate than the $0.1 \%$ dose. ${ }^{42}$

\section{Discussion and future directions}

Suboptimal results after phacoemulsification are not well tolerated in today's world with advanced intraocular lenses, advanced intraoperative techniques and increasingly active patients with high demands. One such suboptimal outcome, $\mathrm{PMO}$, is a comparatively uncommon condition; however, the increasing frequency of cataract surgery and the growing need for lens replacement in ageing populations has increased its incidence and raised the importance of preventive treatments. ${ }^{1,2,-9}$ PMO prevention is particularly important in patients with diabetes and/or uveitis who are at a greater risk than those without these factors. ${ }^{124,26}$ Uveitis is an important sign in patients with a history of retinal vein occlusion. It is also an important sign in patients with glaucoma who should stop receiving prostaglandin therapy prior to cataract surgery. ${ }^{11,24,28}$ Various studies have indicated the benefits of NSAIDS in the prevention of PMO but there is a lack of level I evidence that supports the long-term benefit of this therapy in preventing vision loss after cataract surgery, even though it may increase the speed of vision recovery in the first few weeks after surgery. ${ }^{32}$ Topical NSAIDS have variable efficacy in PMO prevention but there is extensive lowerlevel evidence that they do provide benefits when used alone or in combination with corticosteroids. ${ }^{32,38,46,52}$
More compelling evidence in favour of NSAIDs in PMO prevention comes from a systematic review that identified 15 randomised trials that met the selection criteria. ${ }^{53}$ The analysis found high-quality evidence that topical NSAIDS are more effective than corticosteroids in preventing PMO after cataract surgery (PMO occurred in 3.8\% of NSAID-treated patients versus $25.3 \%$ of corticosteroid-treated patients; risk ratio 5.35 ; 95\% Cl: 2.94-9.76). This analysis also found low- to moderate-quality evidence that topical NSAIDs are more effective than corticosteroids in preventing post-operative inflammation after cataract surgery.

Among the NSAIDs, in the clinical trials discussed, 0.1\% NPF (three times daily) has consistently shown significant efficacy in reducing PMO incidence in terms of evidence of angiographic leakage, macular thickness and measures of visual acuity, and the treatment is well tolerated with little difference in adverse events between the treatment and vehicle only. To reduce the required frequency of dosing and improve convenience, phase III clinical trials have shown similar findings in that the higher 0.3\% NPF formulation is effective in PMO prevention when dosed once daily.

The two recent European phase III studies did not compare the $0.3 \%$ NPF dose regimen with the $0.1 \%$ NPF dose regimen, but comparisons between studies suggest that the former achieves similar efficacy outcomes without changing the safety profile. ${ }^{50}$ The more convenient 0.3\% NPF dosing schedule also has the potential to improve patient compliance and outcomes. However, the earlier phase III trial conducted in the US and Europe ${ }^{49}$ was only powered to show non-inferiority of $0.3 \%$ NPF compared with the $0.1 \%$ NPF regimen, so it is not possible to state whether the $0.3 \%$ dose is superior.

Further evaluation of NSAIDS in PMO prevention is needed. This would further justify their use and identify which are more effective and tolerable. Data from such studies may encourage greater use of PMO preventive medication in the future and help decrease inflammation leading to reduced vision damage in a sizeable population of patients who are about to undergo or have recently undergone cataract surgery.
1. Chu CJ, Johnston RL, Buscombe C, et al. Risk factors and incidence of macular edema after cataract surgery: A database study of 81984 eyes. Ophthalmology. 2016;123:316-23. 2010. Br J Ophthalmol. 2012;96:614-8.

3. World Health Organisation. Blindness: Vision 2020 - The Global
Initiative for the Elimination of Avoidable Blindness. 2017. Available at: www.who.int/mediacentre/factsheets/fs213/en/ (accessed 14 March 2017). 
4. Ellwein LB, Lepkowski JM, Thulasiraj RD, et al. The cost effectiveness of strategies to reduce barriers to cataract surgery. The Operations Research Group. Int Ophthalmol. 1991;15:175-83

5. Khandekar R, Sudhan A, Jain BK, et al. Impact of cataract surgery in reducing visual impairment: a review. Middle East Afr J Ophthalmol. 2015;22:80-5.

6. Rao GN, Khanna R, Payal A. The global burden of cataract Curr Opin Ophthalmol. 2011:22:4-9.

7. Flach AJ. The incidence, pathogenesis and treatment of cystoid macular edema following cataract surgery. Trans Am Ophthalmol Soc. 1998;96:557-634.

8. Lobo C. Pseudophakic cystoid macular edema Ophthalmologica. 2012;227:61-7.

9. Yonekawa Y, Kim IK. Pseudophakic cystoid macular edema. Curr Opin Ophthalmol. 2012;23:26-32.

10. Lindstrom R. Review of OphthalmologyThoughts on Cataract Surgery: 2015. Available at: www.reviewofophthalmology. com/article/thoughts-on-cataract-surgery-2015 (accessed 20 February 2018).

11. Ray S, D'Amico DJ. Pseudophakic cystoid macular edema. Semin Ophthalmol. 2002;17:167-80.

12. Almeida DR, Khan Z, Xing L, et al. Prophylactic nepafenac and ketorolac versus placebo in preventing postoperative macular edema after uneventful phacoemulsification. J Cataract Refract Surg. 2012:38:1537-43.

13. Mathys KC, Cohen KL. Impact of nepafenac $0.1 \%$ on macular thickness and postoperative visual acuity after cataract surgery in patients at low risk for cystoid macula cataract surgery in patients at low risk

14. Miyake K, Ota I, Miyake $G$, et al. Nepafenac $0.1 \%$ versus fluorometholone $0.1 \%$ for preventing cystoid macular edema after cataract surgery. J Cataract Refract Surg. 2011;37:1581-8.

15. Pollack A, Staurenghi $G$, Sager $D$, et al. Prospective randomised clinical trial to evaluate the safety and efficacy of nepafenac $0.1 \%$ treatment for the prevention of macular oedema associated with cataract surgery in patients with diabetic retinopathy. Br J Ophthalmol. 2017;101:423-7.

16. Ramakrishnan $\mathrm{S}$, Baskaran $\mathrm{P}$, Talwar $\mathrm{B}$, et al. Prospective, randomized study comparing the effect of $0.1 \%$ nepafenac and $0.4 \%$ ketorolac tromethamine on macular thickness in cataract surgery patients with low risk for cystoid macular edema. Asia Pac J Ophthalmol (Phila). 2015;4:216-20.

17. Singh $R$, Alpern $L$, Jaffe $G$, et al. Evaluation of nepafenac in prevention of macular edema following cataract surge in patients with diabetic retinopathy. Clin Ophthalmo. 2012;6:1259-69

18. Zaczek $A$, Artzen $D$, Laurell $C G$, et al. Nepafenac $0.1 \%$ plus dexamethasone $0.1 \%$ versus dexamethasone alone: effect on macular swelling after cataract surgery. I Cataract Refract Surg. 2014;40:1498-505.

19. European Medicines Agency. Assessment report Nevanac International non-proprietary name: NEPAFENAC Procedure No. EMEA/H/C/000818/X/0016, 2013. Available at: unw. ema.europa.eu/docs/en GB/document_library/EPAR Assessment_Report__-_Variation/human/000818/WC500147891. pdf (accessed 17 March 2017).

20. US Food and Drug Administration. Drug Approval Package: Nevanac (Nepafenac) Ophthalmic suspension 2005. Available at: muraccessdata fda gov/drugsatfda docs/nda/2005/ 021862s000_Nevanac_approv.pdf (accessed 17 March 2017).

21. Schepens $C L$, Avila MP, Jalkh AE, et al. Role of the vitreous in cystoid macular edema. Surv Ophthalmol. 1984;28
Suppl:499-504

22. Cunha-Vaz JG, Travassos A. Breakdown of the blood-retinal barriers and cystoid macular edema. Surv Ophthalmol. 1984;28 Suppl:485-92.

23. Rossetti L, Autelitano A. Cystoid macular edema following cataract surgery. Curr Opin Ophthalmol. 2000;11:65-72.

24. Loewenstein A, Zur D. Postsurgical cystoid macular edema. Dev Ophthalmol. 2010;47:148-59.

25. Augustin A, Loewenstein A, Kuppermann BD. Macular edem . General pathophysiology Dev Ophthalmol. 2010:47:10-26.

26. Rotsos TG, Moschos MM. Cystoid macular edema. Clin Ophthalmol. 2008;2:919-30.

27. Mentes J, Erakgun T, Afrashi F, et al. Incidence of cystoid macular edema after uncomplicated phacoemulsification. Ophthalmologica. 2003;217:408-12.

28. Belair ML, Kim SJ, Thorne JE, et al. Incidence of cystoid macular edema after cataract surgery in patients with and without uveitis using optical coherence tomography. Am J Ophthalmol. 2009;148:128-35 e2

29. Levitz L, Reich J, Roberts TV, et al. Incidence of cystoid macular edema: femtosecond laser-assisted cataract surgery versus manual cataract surgery. I Cataract Refract Surg. 2015;41:683-6

30. Daien V, Papinaud L, Domerg C, et al. Incidence and characteristics of cystoid macular edema after cataract surgery. Ophthalmology. 2016:123:663-4.

31. Hoffman RS, Braga-Mele R, Donaldson K, et al. Cataract surgery and nonsteroidal antiinflammatory drugs. I Cataract Refract Surg. 2016;42:1368-79.

32. Kim SJ, Schoenberger SD, Thorne JE, et al. Topical nonsteroida anti-inflammatory drugs and cataract surgery: A report by the American Academy of Ophthalmology. Ophthalmology. 2015;122:2159-68.

33. Lim BX, Lim CH, Lim DK, et al. Prophylactic non-steroida anti-inflammatory drugs for the prevention of macular oedema after cataract surgery. Cochrane Database Syst Rev. 2016;11:CD006683

34. Cervantes-Coste G, Sanchez-Castro YG, Orozco-Carroll M, et al. Inhibition of surgically induced miosis and prevention of postoperative macular edema with nepafenac. Clin Ophthalmol. 2009:3:219-26.

35. Quintana NE, Allocco AR, Ponce JA, et al. Non steroidal anti-inflammatory drugs in the prevention of cystoid macular edema after uneventful cataract surgery. Clin Ophthalmol. 2014:8:1209-12

36. Shorstein $\mathrm{NH}$, Liu L, Waxman MD, et al. Comparative effectiveness of three prophylactic strategies to prevent clinical macular edema after phacoemulsification surgery. Ophthalmology. 2015;122:2450-6.

37. Wolf EJ, Braunstein A, Shin C, et al. Incidence of visually significant pseudophakic macular edema after uneventfur phacoemulsification in patients treated with nepafenac. J Cataract Refract Surg. 2007;33:1546-9.

38. Warren KA, Bahrani H, Fox JE. NSAIDs in combination therapy for the treatment of chronic pseudophakic cystoid macular edema. Retina. 2010;30:260-6.

39. Henderson BA, Kim JY, Ament CS, et al. Clinical pseudophakic cystoid macular edema. Risk factors for development and duration after treatment. I Cataract Refract Surg. 2007;33:1550-8.

40. Schmier JK, Covert DW. Hulme-Lowe CK, et al. Treatment costs of cystoid macular edema among patients following cataract surgery. Clin Ophthalmol. 2016:10:477-83.

41. Rodrigues EB, Farah ME, Bottos JM, et al. Nonsteroidal anti- inflammatory drugs in the treatment of retinal diseases Dev Ophthalmol. 2016;55:212-20.

42. Jones BM, Neville MW. Nepafenac: an ophthalmic nonsteroidal antiinflammatory drug for pain after cataract surgery. Ann Pharmacother. 2013;47:892-6.

43. Lane SS. Nepafenac: a unique nonsteroidal prodrug. Int Ophthalmol Clin. 2006:46:13-20.

44. Lindstrom R, Kim T. Ocular permeation and inhibition of retina inflammation: an examination of data and expert opinion on the clinical utility of nepafenac. Curr Med Res Opin. 2006;22:397-404.

45. Takahashi K, Saishin Y, Saishin Y, et al. Topical nepafenac inhibits ocular neovascularization. Invest Ophthalmol Vis SCi. 2003:44:409-15.

46. Cardascia N, Palmisano C, Centoducati T, et al. Topical nonsteroidal anti-inflammatory drugs as adjuvant therapy in the prevention of macular edema after cataract surgery. Int Ophthalmol. 2016;37:1127-31.

47. Palacio C, Fernandez De Ortega L, Bustos FR, et al. Bromfenac $0.09 \%$ bioavailability in aqueous humor, prophylactic effect on cystoid macular edema, and clinical signs of ocular inflammation after phacoemulsification in a Mexican population. Clin Ophthalmol. 2016;10:233-7.

48. Zhao X, Xia S, Wang E, et al. Comparison of the efficacy and patients' tolerability of Nepafenac and Ketorolac in the treatment of ocular inflammation following cataract surgery: A meta-analysis of randomized controlled trials. PLOS One. 2017;12:e0173254.

49. Modi SS, Lehmann RP, Walters TR, et al. Once-daily nepafenac ophthalmic suspension $0.3 \%$ to prevent and treat ocular inflammation and pain after cataract surgery: phase 3 study. Cataract Refract Surg. 2014;40:203-11.

50. Singh RP, Lehmann R, Martel J, et al. Nepafenac $0.3 \%$ after cataract surgery in patients with diabetic retinopathy: Results of 2 randomized phase 3 studies. Ophthalmology. 2017; $124: 776-85$.

51. McCafferty S, Harris A, Kew C, et al. Pseudophakic cystoid macular edema prevention and risk factors; prospective study with adjunctive once daily topical nepafenac $0.3 \%$ versus placebo. BMC Ophthalmol. 2017;17:16

52. Duan P, Liu Y, Li J. The comparative efficacy and safety of topical non-steroidal anti-inflammatory drugs for the treatment of anterior chamber inflammation after cataract surgery: a systematic review and network meta-analysis. Graefes Arch Clin Exp Ophthalmol. 2017:255:639-49.

53. Kessel L, Tendal B, Jorgensen KJ, et al. Post-cataract prevention of inflammation and macular edema by steroid and nonsteroidal anti-inflammatory eye drops: a systematic review. Ophthalmology. 2014;121:1915-24.

54. Lally DR, Shah CP. Pseudophakic cystoid macular edemaPseudophakic CME remains a common cause of reduced vision after cataract surgery. A look at its causes and treatment. 2014. Review of Ophthalmology. Available at: www. reviewofophthalmology.com/article/pseudophakic-cystoidmacular-edema (accessed 23 July 2018).

55. Clinicaltrials.gov. Nepafenac Once Daily for Macular Edema - Study 2. Clinical Trials.gov Identifier. NCT01872611. Available at: https://clinicaltrials.gov/ct2/show/NCT01872611 (accessed 23 July 2018)

56. Singh RP, Staurenghi G, Pollack A, et al. Efficacy of nepafenac ophthalmic suspension $0.1 \%$ in improving clinical outcomes following cataract surgery in patients with diabetes: an analysis of two randomized studies. Clin Ophthalmol. 2017;11:1021-9. 